\begin{tabular}{lll}
\hline Jurnal Teknologi Kimia Unimal & $\begin{array}{l}\text { Jurnal } \\
\text { Teknologi } \\
\text { Kimia } \\
\text { Unimal }\end{array}$ \\
\hline
\end{tabular}

\title{
Pengaruh Jumlah Ragi dan Waktu Fermentasi terhadap Kadar Bioetanol yang Dihasilkan dari Fermentasi Kulit Pepaya
}

\author{
Nasrun $^{1}$, Jalaluddin ${ }^{2}$, Mahfuddhah ${ }^{3}$ \\ 1,2,3 Jurusan Teknik Kimia, Fakultas Teknik, Universitas Malikussaleh \\ Laboratorium Teknik Kimia, Jl. Batam No. 2 Bukit Indah, Lhokseumawe 24353 \\ Korespondensi: HP: 085260055045, e-mail: nasrun_ibrahim@yahoo.com
}

\begin{abstract}
Abstrak
Bioetanol memiliki banyak fungsi dan kegunaan, diantaranya sebagai pelarut. Bioetanol belakangan ini dikenal sebagai salah satu bahan bakar alternatif yang cukup potensial, selain dapat dibuat dengan mudah dan dengan biaya murah,bioetanol juga dapat dibuat dari berbagai bahan baku yang ada di alam. Pada penelitian ini dibuat bioetanol dari kulit pepaya, tujuannya adalah untuk mengkaji pengaruh jumlah ragi dan waktu fermentasi terhadap jumlah bioetanol yang diperoleh. Hasil penelitian didapatkan bahwa volume bioetanol tertinggi 31,17 ml didapatkan pada perlakuan waktu fermentasi selama 4 hari dan penambahan ragi Saccaromyces cereviceae sebanyak 15 gram, densitas bioetanol tertinggi diperoleh pada jumlah ragi 15 gram dengan waktu fermentasi 4 hari yaitu $0,883 \mathrm{gr} / \mathrm{ml}, \mathrm{pH}$ media tertinggi selama fermentasi yaitu 5 yang terdapat pada jumlah ragi 20 gram dengan waktu fermentasi 3, 4, dan 5 hari. Rendemen bioetanol yang paling tinggi diperoleh pada jumlah ragi 15 gram dengan waktu fermentasi 4 hari yaitu sebesar 6,23\%.
\end{abstract}

Kata kunci: bioetanol, kulit pepaya, fermentasi, ragi

\section{Pendahuluan}

Penyediaan energi pada masa depan merupakan permasalahan yang senantiasa menjadi perhatian semua bangsa karena kesejahteraan manusia dalam kehidupan moderen sangat terkait dengan jumlah dan mutu energi yang dimanfaatkan. Penyediaan energi merupakan faktor yang sangat penting dalam mendorong pembangunan terutama bagi negara yang sedang berkembang seperti Indonesia. Seiring dengan meningkatnya pembangunan, kebutuhan akan energi terus meningkat, terutama pembangunan di sektor industri, pertumbuhan ekonomi, dan pertumbuhan penduduk. Sampai saat ini, minyak bumi merupakan sumber energi utama dalam memenuhi kebutuhan di dalam negeri. Selain itu 
minyak bumi juga berperan sebagai sumber devisa negara. Peranan minyak bumi yang besar tersebut terus berlanjut, sedangkan cadangan semakin menipis. Selain itu, produksi bahan bakar minyak (BBM) yang dilakukan melalui teknologi transformasi di dalam negeri tidak mencukupi dengan jumlah kebutuhannya.

Pemanfaatan energi alternatif sedang digalakkan guna mengurangi ketergantungan terhadap bahan bakar minyak (BBM) di mana salah satunya adalah pemanfaatan bioetanol. Bioetanol berasal dari fermentasi jagung, sagu, pepaya, nira tebu, nenas dan sejenisnya. Bioetanol dapat digunakan untuk pelarut. Kandungan dalam bioetanol adalah etanol (alkohol) yang sifatnya mudah menguap. Alkohol berupa larutan jernih tak berwarna, beraroma khas yang dapat diterima, berfasa cair pada temperatur kamar, dan mudah terbakar. Etanol dikategorikan dalam dua kelompok yaitu etanol berhidrat (etanol 95-96 \%) dan etanol unhidrat (etanol > 99,6 \%). Etanol kelompok kedua adalah etanol yang digunakan sebagai bahan bakar dan disebut fuel grade ethanol (FGE) (Zubaidah, 2010).

Produksi bioetanol dari tanaman yang mengandung glukosa yang selanjutnya dilakukan proses fermentasi atau peragian dengan menambahkan yeast atau ragi sehingga diperoleh bioetanol sebagai sumber energi. Menurut Fitriani (2012) pembuatan bioetanol dari sari kulit nanas dipengaruhi oleh jenis ragi dan jumlah ragi yang dipakai, fermentasi menggunakan ragi roti dapat menghasilkan kadar bioetanol yang lebih tinggi daripada penggunaan ragi tape. Dari hasil penelitian tersebut disimpulkan bahwa variabel terbaik diperoleh pada waktu fermentasi 4 dan 5 hari dengan jumlah ragi roti 4 gram dari bahan baku kulit nanas 200 gr di mana diperoleh bioetanol dengan kadar $70 \%$ dengan volume $16 \mathrm{ml}$, sedangkan pada ragi tape kadar bioetanol yang diperoleh sebesar $65 \%$ dengan volume $14 \mathrm{ml}$. Penelitian ini akan menggunakan bahan baku kulit pepaya dengan memvariasikan jumlah ragi dan waktu fermentasi.

Penelitian ini bertujuan untuk mengkaji pengaruh jumlah ragi dan waktu fermentasi terhadap jumlah bioetanol yang dihasilkan dari kulit pepaya. Diharapkan manfaat penelitian ini adalah dapat memberikan informasi atau gambaran kepada masyarakat pada umumnya mengenai pembuatan bioetanol 
sebagai energi pengganti alternatif, mengingat bioetanol adalah bahan bakar alternatif yang dapat diperbarui dan ramah lingkungan.

\section{Bahan dan Metode}

Bahan-bahan dan peralatan yang digunakan dalam penelitian ini antara lain adalah kulit pepaya, ragi roti, urea, pupuk NPK, aquades, timbangan analitik, blender, selang plastik, penyaring, penangas air, dan lain-lain. Penelitian ini dilakukan dalam skala laboratorium dengan tahap persiapan bahan baku kemudian dilanjutkan dengan proses pembuatan bioetanol berbahan dasar kulit pepaya dengan proses fermentasi menggunakan ragi roti dengan variasi (10, 15 dan 20 gr) dan waktu fermentasi (3, 4 dan 5 hari). Tahapan analisa meliputi analisa densitas, analisa $\mathrm{pH}$, rendemen, dan volume etanol.

Tahap pengerjaannya adalah 500 gr sampel yang telah disediakan dimasukkan ke dalam reaktor fermentasi. Pupuk NPK, urea, dan ragi roti dimasukkan ke dalam air aquades yang sesuai dengan variabel yang telah ditetapkan hingga terbentuk busa. Kemudian dimasukkan ke dalam reaktor fermentasi pada suhu $35{ }^{\circ} \mathrm{C}$ dan dibiarkan selama 3 hari kemudian dilakukan penyaringan, selanjutnya dilakukan proses distilasi. Produk distilat yang diperoleh disimpan dalam botol. Tahap analisa adalah tahap pengukuran densitas, $\mathrm{pH}$, dan rendemen.

\section{Hasil dan Diskusi}

Bioetanol dihasilkan dari gula yang merupakan hasil aktivitas fermentasi sel khamir. Khamir yang baik digunakan untuk menghasilkan bioetanol adalah dari genus Saccharomyces. Saccharomyces cerevisiae menghasilkan enzim zimase dan invertase. Enzim zimase berfungsi sebagai pemecah sukrosa menjadi monosakarida (glukosa dan fruktosa). Enzim invertase selanjutnya mengubah glukosa menjadi bioetanol (Judoamidjojo dkk, 1992). Kriteria pemilihan khamir untuk produksi bioetanol adalah mempunyai laju fermentasi dan laju pertumbuhan cepat, perolehan bioetanol banyak, tahan terhadap konsentrasi bioetanol dan glukosa tinggi, tahan terhadap konsentrasi garam tinggi, $\mathrm{pH}$ optimum fermentasi 
rendah, temperatur optimum fermentasi sekitar 25-30 ${ }^{\circ} \mathrm{C}$. Data hasil penelitian dapat dilihat dalam Tabel 1.

Tabel 1 Data hasil penelitian

\begin{tabular}{|c|c|c|c|c|c|c|}
\hline No & $\begin{array}{c}\text { Waktu } \\
\text { Fermentasi } \\
\text { (hari) }\end{array}$ & $\begin{array}{l}\text { Jumlah } \\
\text { Ragi (gr) }\end{array}$ & $\begin{array}{c}\text { Volume } \\
\text { Etanol } \\
(\mathrm{ml})\end{array}$ & $\begin{array}{c}\text { Densitas } \\
(\mathrm{gr} / \mathrm{ml})\end{array}$ & $\begin{array}{c}\mathrm{pH} \\
\text { Fermentasi }\end{array}$ & $\begin{array}{c}\text { Rendemen } \\
(\%)\end{array}$ \\
\hline \multirow{3}{*}{1.} & \multirow{3}{*}{3} & 10 & 28,73 & 0,862 & 4 & 5,746 \\
\hline & & 15 & 29,58 & 0,870 & 4 & 5,916 \\
\hline & & 20 & 26,67 & 0,847 & 5 & 5,334 \\
\hline \multirow{3}{*}{2.} & \multirow{3}{*}{4} & 10 & 29,92 & 0,874 & 4 & 5,984 \\
\hline & & 15 & 31,17 & 0,883 & 4 & 6,234 \\
\hline & & 20 & 28,29 & 0,878 & 5 & 5,658 \\
\hline \multirow{3}{*}{3.} & \multirow{3}{*}{5} & 10 & 28,12 & 0,838 & 4 & 5,658 \\
\hline & & 15 & 26,93 & 0,839 & 5 & 5,386 \\
\hline & & 20 & 26,30 & 0,833 & 5 & 5,260 \\
\hline
\end{tabular}

Faktor yang dapat mempengaruhi jumlah bioetanol yang dihasilkan dari fermentasi adalah mikroorganisme dan media yang digunakan (Astuty, 1991). Selain itu hal yang perlu diperhatikan selama fermentasi adalah pemilihan khamir, konsentrasi gula, keasaman, ada tidaknya oksigen dan suhu dari perasan buah. Pemilihan sel khamir didasarkan pada jenis karbohidrat yang digunakan, sebagai medium untuk memproduksi alkohol dari pati dan gula digunakan Saccharomyces cerevisiae. Suhu yang baik untuk proses fermentasi berkisar antara 25-30 ${ }^{\circ} \mathrm{C}$. Derajat keasaman $(\mathrm{pH})$ optimum untuk proses fermentasi sama dengan $\mathrm{pH}$ optimum untuk proses pertumbuhan khamir yaitu $\mathrm{pH}$ 4,0 - 5,0.

\subsection{Pengaruh Waktu Fermentasi dan Jumlah Ragi Terhadap Volume Bioetanol}

Semakin lama waktu fermentasi maka jumlah mikroba semakin menurun, dan akan menuju ke fase kematian karena alkohol yang dihasilkan semakin 
banyak dan nutrient yang ada sebagai makanan mikroba semakin menurun (Kunaepah, 2008). Gambar 1 menunjukkan bahwa volume bioetanol tertinggi 31,17 ml didapatkan pada perlakuan waktu fermentasi selama 4 hari dan penambahan ragi Saccaromyces cereviceae sebanyak 15 gram.

Menurut Asngad dkk (2011), semakin lama proses fermentasi dan semakin banyak dosis ragi yang diberikan maka volume bioetanol semakin meningkat. Volume bioetanol yang tertinggi diperoleh pada waktu fermentasi 15 hari. Hal ini menunjukkan bahwa pada waktu tersebut aktivitas khamir Saccaromyces cerevisiae bekerja secara optimal serta kegiatan enzimatis tidak terhambat. Waktu fermentasi berpengaruh terhadap hasil perolehan bioetanol di mana semakin lama waktu fermentasi maka perolehan bioetanol akan meningkatkan. Namun bila fermentasi terlalu lama maka nutrisi dalam substrat akan habis dan khamir Saccaromyces cerevisiae tidak lagi dapat memfermentasi bahan. Pada perlakuan penambahan 20 gram Saccaromyces cerevisiae, dan waktu fermentasi 5 hari diperoleh volume bioetanol 26,30 $\mathrm{ml}$, sedikit lebih rendah bila dibandingkan dengan perlakuan penambahan 15 g Saccaromyces cerevisiae di mana diperoleh kadar bioetanol 26,93 ml. Hal ini dikarenakan jumlah nutrisi yang tersedia tidak sebanding dengan jumlah Saccaromyces cerevisiae yang lebih banyak, sehingga Saccharomyces cereviceae kekurangan makanan yang mengakibatkan kinerja Saccharomyces cereviceae menurun dan mengakibatkan volume bioetanol yang dihasilkan akan menurun juga. Hasil penelitian volume bioetanol diperlihatkan pada Gambar 1.

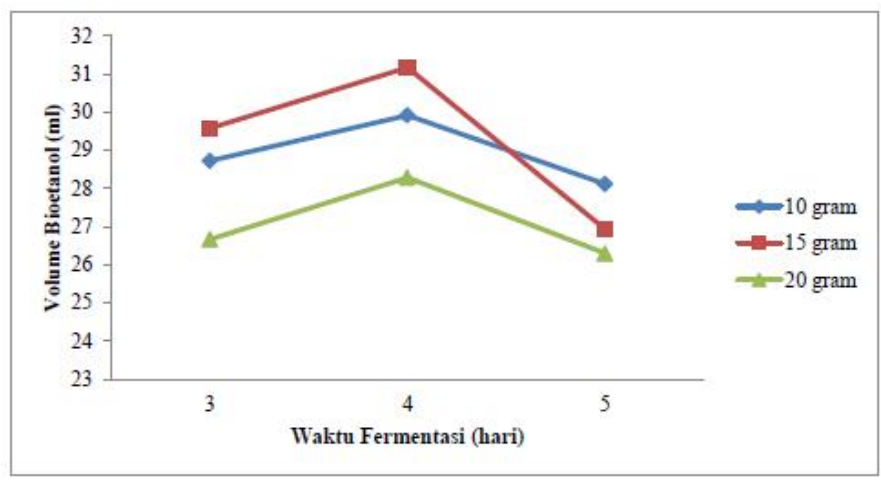

Gambar 1 Pengaruh waktu fermentasi dan jumlah ragi terhadap perolehan Bioetanol 


\subsection{Pengaruh Waktu Fermentasi dan Jumlah Ragi Terhadap Densitas Bioetanol}

Densitas adalah massa dari suatu zat dalam setiap satuan volume. Dari Gambar 2 dapat dilihat bahwa densitas bioetanol tertinggi diperoleh pada jumlah pemakaian ragi 15 gram dengan waktu fermentasi 4 hari yaitu $0,883 \mathrm{gr} / \mathrm{ml}$. Sementara itu pada pemakaian ragi 15 gram dengan waktu fermentasi 3 hari, densitas bioetanol yang diperoleh adalah $0,870 \mathrm{gr} / \mathrm{ml}$. Pada pemakaian ragi 15 gram dengan waktu fermentasi 5 hari densitasnya adalah $0,839 \mathrm{gr} / \mathrm{ml}$. Hasil penelitian ini menunjukkan bahwa pengaruh jumlah ragi yang optimal yaitu pada jumlah ragi 15 gram dengan waktu fermentasi 4 hari.

Semakin banyak jumlah ragi yang diberikan dan semakin lama waktu fermentasi maka densitas bioetanol yang diperoleh juga semakin besar, hal ini menunjukkan bahwa jumlah ragi dan waktu fermentasi pada saat fermentasi sangat berpengaruh terhadap densitas bioetanol yang dihasilkan di mana pada kondisi ini bakteri lebih aktif bekerja untuk mengubah glukosa menjadi bioetanol. Akan tetapi pada waktu fermentasi 5 hari densitas menurun yang menunjukkan bahwa pada waktu tersebut Saccaromyces cerevisiae memasuki death phase sehingga jumlah mikroba yang tumbuh semakin melambat dan tidak ada penambahan jumlah mikroba yang dapat mengubah substrat menjadi bioetanol sehingga bioetanol yang dihasilkan cendrung turun. Hasil tersebut dapat dilihat pada Gambar 2.

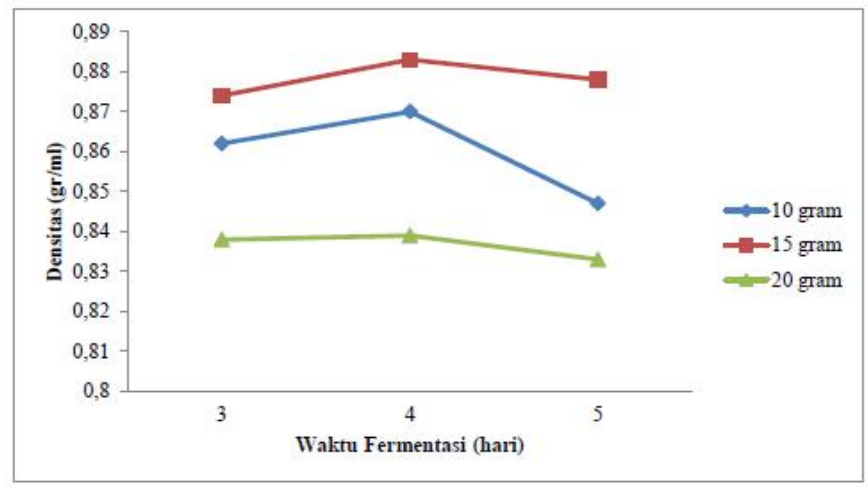

Gambar 2 Pengaruh waktu fermentasi dan jumlah ragi terhadap densitas bioetanol 


\subsection{Pengaruh Waktu Fermentasi dan Jumlah Ragi Terhadap pH Bioetanol}

Keasaman atau $\mathrm{pH}$ medium merupakan salah satu faktor penting yang mempengaruhi pertumbuhan mikroorganisme dan pembentukan produk dalam proses fermentasi karena setiap mikroorganisme mempunyai kisaran $\mathrm{pH}$ optimal terhadap lingkungan hidupnya.

Dalam proses fermentasi terjadi penurunan. Perubahan $\mathrm{pH}$ dalam fermentasi disebabkan karena dalam aktivitasnya sel khamir selain menghasilkan etanol sebagai metabolit primer juga menghasilkan asam-asam organik seperti asam malat, asam tartarat, asam sitrat, asam laktat, asam asetat, asam butirat dan asam propionat sebagai hasil sampingan, asam ini menurunkan $\mathrm{pH}$ medium. Hasil pH bioetanol diperlihatkan pada Gambar 3.

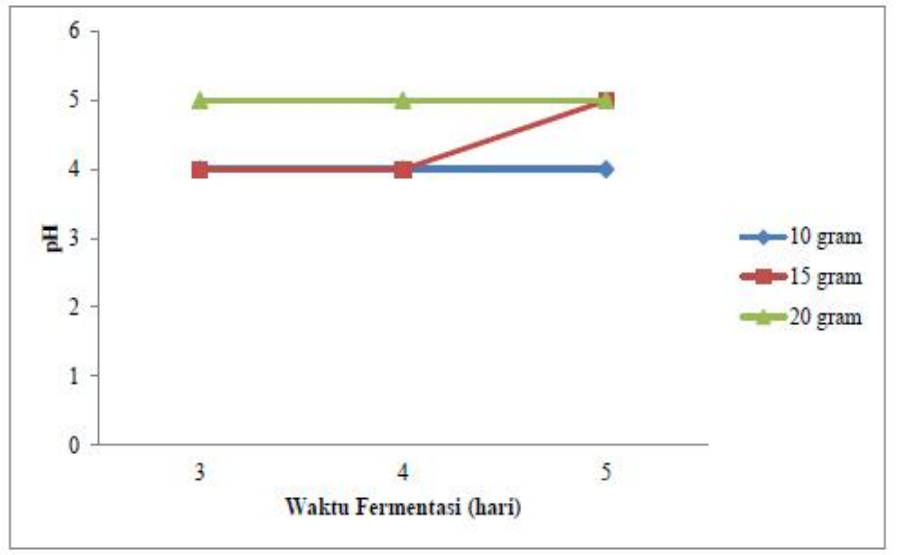

Gambar 3 Pengaruh waktu fermentasi terhadap pH bioetanol

Gambar 3 menunjukkan $\mathrm{pH}$ media tertinggi selama fermentasi yaitu 5, pada jumlah ragi 20 gram dengan waktu fermentasi 3, 4 dan 5 hari dan pada jumlah ragi 15 gram dengan waktu fermentasi 5 hari. Jadi dapat disimpulkan bahwa proses fermentasi berjalan dengan cukup baik, karena derajat keasaman $(\mathrm{pH})$ optimum untuk proses fermentasi sama dengan $\mathrm{pH}$ optimum untuk proses pertumbuhan khamir yaitu $\mathrm{pH} 4,0-5,0$. 
Nasrun dkk. / Jurnal Teknologi Kimia Unimal 4 : 2 (November 2015) 1-10

\subsection{Pengaruh Waktu Fermentasi dan Jumlah Ragi Terhadap Rendemen Bioetanol}

Gambar 4 menunjukkan rendemen bioetanol yang paling tinggi diperoleh pada jumlah ragi 15 gram dengan waktu fermentasi 4 hari sebesar 6,234 \%, untuk jumlah ragi 10 gram dengan waktu fermentasi 4 hari diperoleh rendemen bioetanol sebesar 5,916\%, sedangkan untuk jumlah ragi 20 gram dengan waktu fementasi 4 hari diperoleh rendemen bioetanol sebesar 5,386\%. Pada penelitian ini menunjukkan pengaruh jumlah ragi yang optimal yaitu pada jumlah ragi 15 gram di mana semakin besar jumlah ragi yang diberikan dan semakin lama waktu fermentasi maka rendemen bioetanol yang diperoleh juga semakin besar, hal ini dikarenakan jumlah ragi dan waktu fermentasi pada saat fermentasi sangat berpengaruh terhadap jumlah rendemen bioetanol yang didapat, tetapi pada perlakuan penambahan 20 gram Saccaromyces cerevisiae, dan waktu fermentasi 5 hari diperoleh rendemen bioetanol 5,260 \% lebih rendah dibandingkan penambahan 10 gram Saccaromyces cerevisiae di mana rendemennya 5,658 \%. Hal ini dikarenakan jumlah nutrisi yang tersedia tidak sebanding dengan jumlah Saccaromyces cerevisiae yang lebih banyak, sehingga Saccharomyces cereviceae kekurangan makanan yang mengakibatkan kinerja Saccharomyces cereviceae menurun dan mengakibatkan rendemen bioetanol yang dihasilkan juga akan menurun. Hasil rendemen bioetanol yang diperoleh diperlihatkan pada Gambar 4.

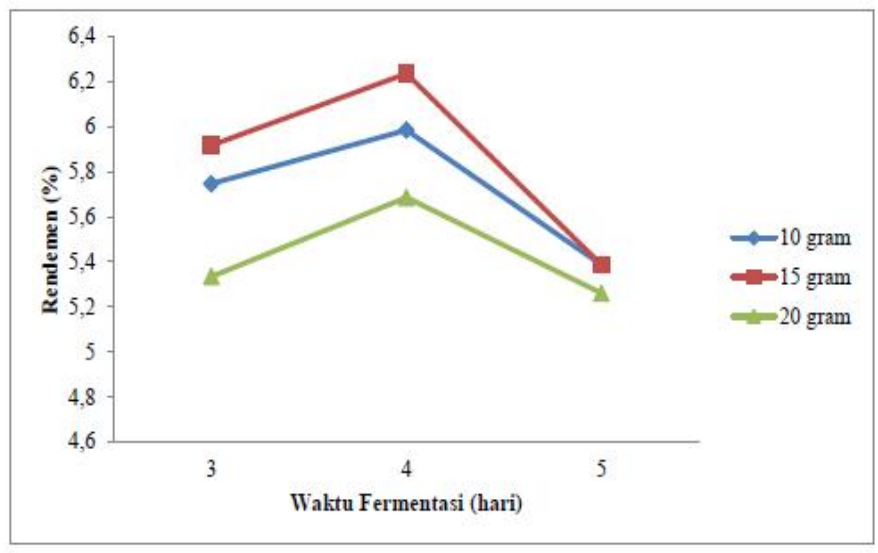

Gambar 4 Pengaruh waktu fermentasi terhadap rendemen bioetanol 
Nasrun dkk. / Jurnal Teknologi Kimia Unimal 4 : 2 (November 2015) 1-10

\section{Simpulan dan Saran}

\subsection{Kesimpulan}

Volume bioetanol tertinggi adalah 31,17 $\mathrm{ml}$ yang diperoleh pada perlakuan waktu fermentasi selama 4 hari dan penambahan ragi Saccaromyces cereviceae sebanyak 15 gram. Densitas bioetanol tertinggi diperoleh pada jumlah ragi 15 gram dengan waktu fermentasi 4 hari yaitu $0,883 \mathrm{gr} / \mathrm{ml}$. $\mathrm{pH}$ media tertinggi selama fermentasi yaitu 5 yang terjadi pada jumlah ragi 20 gram dengan waktu fermentasi 3, 4 dan 5 hari dan pada jumlah ragi 15 gram dengan waktu fermentasi 5 hari. Rendemen bioetanol yang paling tinggi diperoleh pada jumlah ragi 15 gram dengan waktu fermentasi 4 hari yaitu sebesar 6,234 \%.

\subsection{Saran}

Penelitian ini masih sebagai tahap awal untuk dapat mengetahui trend dari variabel- variabel yang diteliti (belum merupakan penelitian optimasi), oleh karena itu perlu dilakukan penelitian optimasi.

\section{Daftar Pustaka}

1. Alexopoulus, C.J and C.W. Mims. 1979. Introductory Tecnology, John Wiley and Sons, New York, hal. 632.

2. Anonim. 2007. Bioetanol Bahan Baku Singkong, The Largest Aceh Community.

3. Arcinthya,R.R. 2007. Karakterisasi Ekstrak Kasar Amilase Isolat bakteri.

4. Achmad Faikar Ali Fauzi. 2011. Pemanfaatan Buah Pepaya Sebagai Bahan Baku Bioetanol dengan Proses Fermentasi dan Distilasi, Universitas Diponegoro. Vol. 1, Hal 1-13.

5. Asngad, Aminah dan Suparti. (2011). Lama Fermentasi dan Dosis Ragi yang Berbeda pada Fermentasi Gaplek Ketela Pohon Varietas Mukibat Terhadap Kadar Glukosa dan Bioetanol, Tersedia pada: http://eprints.ums.ac.id/1385/1/1._ANAH_ASN GAD.pdf .

6. Astuty ED. (1991). Fermentasi Etanol Kulit Buah Pisang, UGM, Yogyakarta. 
7. Chairul, Birri. 2008. Pembuatan Bioetanol dari Umbi Kayu dengan Menggunakan Proses Hidrolisa Enzimatik, TGA, Politeknik Negeri Lhokseumawe.

8. Charles Wyman. 1996. Production and Utilization: Handbook on Bioethanol.

9. Datar, R. P., R. M. Shenkman, B. G. Cateni, R. L. Huhnke, R. S. Lewis. 2004. Fermentation. of biomass-generated producer gas to ethanol, Biotechnology and Bioengineering, 86 (5): 587-594.

10. Elevri, P. A. dan S. P. Putra. 2006. Produksi etanol menggunakan Saccharomyces cerevisiae yang diamobilisasi dengan agar batang, Akta Kamindo 1 (2): 105-114.

11. Fardiaz, S. 1992. Mikrobiologi Pangan 1, Gramedia Pustaka Utama, Jakarta.

12. Fitriani. 2012. Pemanfaatan Sari Kulit Nanas Sebagai Bahan Pembuatan Bioetanol dengan Menggunakan Metode Fermentasi, TGA, Universitas Malikussaleh Lhokseumawe.

13. Fersenden R.J dan Joan S. 1989. Kimia Organik Jilid I, Jakarta, Erlangga. Hambali et al. 2007. Teknologi Bioenergi. Jakarta : Agromedia Pustaka.

14. Jefri Sagala. Pembuatan dan Pemurnian Bioetanol dari Buah Pepaya Menggunakan Proses Fermentasi dan Distilasi, Universitas Negeri Medan, 2 (1): 4.

15. Nurdianti, F. 2007. Evaluasi Aktivitas Enzim Glukoamilase dari Aspergillus Oryzae dengan Umbi Jalar dan Umbi kayu sebagai Substrat, Skripsi Fakultas Sains dan Teknik Jurusan MIPA Program Studi Kimia Unsoed Purwokerto.

16. Pinus dan Marsono. 2009. Petunjuk Penggunaan Pupuk, Jakarta, Penebar Swadaya.

17. Prihandana, Rama. 2007. Bioetanol Ubi Kayu, Cet. Pertama, Jakarta: Agromedia Pustaka.

18. Rikana, Heppy. 2010. Pembuatan Bioetanol dari Singkong Secara Fermentasi Menggunakan Ragi Tape, Universitas Diponegoro, Semarang.

19. Trifosa D. 2007. Konversi Pati Jagung Menjadi Bioetanol, Tugas Akhir Program Studi Kimia FMIPA ITB.

20. Zubaidah, Elok, 2012. perbedaan kondisi, fermentasi Alkohol dan konsentrasi inokulum pada pembuatan cuka salak; Universitas Brawijaya. 